\title{
Penerapan Konsep Modern Natural dengan Sentuhan Etnik Tengger Pada Desain Interior Hotel Bromo Permai 1
}

\author{
Riski Puspita dan Prasetyo Wahyudie \\ Jurusan Desain Interior, Fakultas Teknik Sipil dan Perencanaan, Institut Teknologi Sepuluh Nopember \\ (ITS) \\ Jl. Arief Rahman Hakim, Surabaya 60111 Indonesia \\ e-mail:prasetyo@prodes.its.ac.id
}

\begin{abstract}
Abstrak-Pariwisata merupakan salah satu sektor yang penting dalam pembangunan negara. Dengan adanya pariwisata, maka akan menarik perkembangan sektor-sektor lain seperti perhutanan, perikanan, pertanian, dan berbagai sektor lainnya. Dengan dibukanya kawasan wisata Taman Nasional Gunung Bromo memberikan dampak yang positif pada daerah terutama sarana akomodasi.

Hotel Bromo Permai 1 merupakan salah satu hotel yang berada di area Taman Nasional Bromo Tengger. Dilihat dari eksisting hotel, dan lokasi yang strategis diperlukan pengolahan konsep lebih lanjut sehingga Hotel Bromo Permai 1 memiliki ciri khas. Mengenai warna, pencahayaan dan suasana di hotel ini dapat dikembangkan untuk menambah kenyamanan serta nilai estetis dalam ruangan.

Metode desain yang digunakan meliputi pengumpulan data yang dilakukan dengan cara survey, observasi dan studi pustaka. Hasil dari metode desain menyimpulkan bahwa konsep desain yang diinginkan mayoritas pengunjung Hotel Bromo Permai 1 selaras dengan tujuan utama desain interior di area wisata yaitu menerapkan konsep kebudayaan untuk memperkenalkan budaya lokal kepada pengunjung yang mayoritas adalah wisatawan yang berasal dari luar daerah, namun tidak melupakan tujuan utamanya sebagai tempat istirahat yang nyaman bagi pengunjung. Hasil yang didapatkan dari desain ini adalah perancangan desain interior Hotel Bromo Permai 1 berkonsep natural modern dengan sentuhan etnik tengger dengan perbandingan sebanyak $70 \%$ konsep natural modern dan $30 \%$ merupakan etnik tengger

Langgam natural modern dan etnik tengger dapat disandingkan menjadi satu-kesatuan desain yang baik dengan memadukan unsur kedua langgam dalam interior. Langgam modern ditampilkan melalui pemilihan warna monokrom sedangkan etnik tengger ditunjukkan dengan adanya transformasi bentuk kebudayaan seperti legenda, tarian, dan pemandangan. Konsep natural modern tengger diterapkan pada 3 area yaitu lobi, restaurant, dan cottage dengan mengolah plafond, dinding, lantai dan elemen estetis, sehingga menciptakan nuansa hangat dan nyaman.
\end{abstract}

Kata Kunci- Etnik Tengger, Hotel Bromo Permai 1, Konsep Natural Modern, Pariwisata.

\section{PENDAHULUAN}

$\mathrm{H}$ OTEL Bromo Permai 1 merupakan hotel yang menjadi tujuan utama wisatawan karena letaknya yang strategis yakni berada di kawasan Taman Nasional Bromo Tengger Semeru. Selain fungsinya sebagai sarana akomodasi untuk menginap, juga dapat digunakan sebagai pembentuk citra atau image dari suatu daerah melalui implementasi budaya yang diterapkan pada interiornya. Namun karena terdapat berbagai aturan khusus bagi hotel yang terletak di kawasan Taman Nasional Bromo Tengger Semeru, desain interior pada hotel yang berada di dalam Taman Nasional menjadi lebih sederhana. Perkembangan hotel yang pesat pada area Taman Nasional Gunung Bromo membuat persaingan antar penyedia jasa penginapan atau hotel menjadi semakin ketat. Konsep desain hotel yang diterapkan dapat diolah lebih lanjut sehingga meningkatkan daya tarik Hotel Bromo Permai 1.

Penyesuaian dan perencanaan ulang pada konsep Hotel Bromo Permai 1 dirasa sangat diperlukan mengingat kondisi hotel pada saat ini. Untuk menarik minat masyarakat, maka perlu diciptakan konsep yang menarik namun sesuai dengan kebudayaan lokal sehingga selain sebagai sarana akomodasi, Hotel Bromo Permai 1 juga dapat berfungsi sebagai sarana edukasi tentang budaya Suku Tengger. Untuk membuat sebuah konsep desain yang sesuai dan menarik, maka diperlukan penelitian yang mendalam. Dengan begitu, dapat dihasilkan konsep desain yang tepat untuk Hotel Bromo Permai 1.

\section{TINJAUAN PUSTAKA}

\section{A. Hotel Bromo Permai 1}

Hotel Bromo Permai 1 berada di kawasan Taman Nasional Bromo - Tengger - Semeru, tepatnya berada di Dusun Cemara Lawang, Desa Ngadisari, Kecamatan Sukapura, Probolinggo, Jawa Timur. Hotel ini mempunyai enam jenis kamar, yaitu Standart Triple, Standart Double, VIP Triple, New Family, Grand Family, dan Cottage.

\section{B. Langgam Natural}

Konsep Natural merupakan konsep yang menonjolkan karakteristik dari bahan bangunan yang diterapkan pada interior. Dalam menciptakan suatu suasana natural pada Interior, terdapat beberapa elemen yang dapat digunakan untuk menghadirkan suasana Natural pada Interior :

- Warna

Gordon (1995) menyatakan bahwa warna yang tercipta berkat adanya cahaya merupakan bentuk energi yang dapat mempengaruhi pikiran (mood) dan emosi. Dalam Desain Grafis, warna mempunyai peran yang sangat penting, karena mempunyai nilai bahasa karakter (Language Character) dan 
efek psikologis terhadap yang melihatnya dan dapat memberikan makna dan kesan tertentu.

- Material

Material yang bersifat natural seperti kayu, batu, bambu, dan vegetasi dapat menghasilkan efek psikologis yang mempengaruhi indera manusia seperti pengelihatan dan peraba.

\section{Modern}

Arsitektur modern mulai berkembang sebagai akibat adanya perubahan dalam teknologi ,sosial, dan kebudayaan yang dihubungkan dengan Revolusi Industri ( 1760 - 1863 ).

Berikut beberapa ciri khas dari langgam modern terkini yang telah mengalami perubahan [1]:

- Terlihat mempunyai keseragaman dalam penggunaan skala manusia.

- Bangunan bersifat fungsional, artinya sebuah bangunan dapat mencapai tujuan semaksimal mungkin, bila sesuai dengan fungsinya.

- Bentuk bangunan sederhana dan bersih yang berasal dari seni kubisme dan abstrak yang terdiri dari bentuk-bentuk aneh, tetapi intinya adalah bentuk segi empat.

- Konstruksi diperlihatkan.

- Pemakaian bahan pabrik yang diperlihatkan secara jujur, tidak diberi ornamen atau ditempel - tempel.

- Interior dan eksterior bangunan terdiri dari garis-garis vertikal dan horisontal.

- Konsep open plan, yaitu membagi dalam elemen-elemen struktur primer dan sekunder, dengan tujuan untuk mendapatkan fleksibelitas dan variasi di dalam bangunan.

\section{Kebudayaan Tengger}

Suku asli yang mendiami kawasan Bromo adalah Suku Tengger. Menurut sejarah, asal - muasal kata Tengger berasal dari gabungan dua kata yaitu Roro Anteng dan Joko Seger (TENG-GER). Hal itu terkait Legenda Roro Anteng dan Joko Seger yang terjadi pada jaman dahulu kalah ketika keturunan Majapahit yang menetap di Bromo [2].

Masyarakat suku Tengger adalah suku tersendiri yang mendiami atau tinggal di kawasan lereng pegunungan Bromo yang terletak di wilayah Kabupaten Probolinggo, Kabupaten Lumajang, Kabupateng Pasuruan, dan Kabupaten Malang, Jawa Timur. Ciri khas dari etnik Tengger diantaranya adalah :

1. Upacara keagamaan

- Upacara Kasada, merupakan ritual keagamaan hindu yang diadakan oleh masyarakat Tengger namun tidak dilakukan oleh pemeluk agama Hindu lain. Upacara ini berkaitan erat mengenai asal usul masyarakat Tengger

- Upacara Karo, merupkan upacara yang dilakukan sebagai wujud syukur masyarakat suku Tengger terhadap para leluhur. Dalam perayaan Karo, terdapat tarian bernama Sodoran. Tarian Sodoran hanya di pertunjukkan pada hari raya Karo ini ditandai dengan sebuah tongkat bamboo berserabut kelapa yang di dalamnya terdapat biji-bijian palawija.

- Upacara Unan-Unan, merupakan upacara yang dilakukan oleh suku Tengger dalam lima tahun sekali atau sewindu sekali menurut penanggalan suku Tengger. Upacara Unanunan ini bisa disebut "mayu bumi", selain itu upacara ini juga bisa disebut "bersih desa" untuk menghindari segala macam gangguan.

\section{Peribadatan}

Menurut Johanes Randy Prakoso dalam artikel (Mengenal Pura Poten, Tempat Ibadah Suku Tengger di Bromo) Tempat beribadah Suku Tengger memiliki letak yang berpisah sesuai dengan komposisi dan tahapan beribadah yang disebut Pura Luhur Poten. Pura Luhur Poten terdiri dari beberapa bangunan yang ditata dalam suatu susunan komposisi di pekarangan yang dibagi menjadi tiga mandala/zona. Masing-masing Mandala Utama (lingkaran warna kuning) yaitu tempat pelaksanaan pemujaan persembahyangan yang di dalamnya sebuah Padma atau tempat pemujaan. Mandala Madya (lingkaran warna merah) sebagai tempat persiapan dan pengiring upacara persembahyangan, Mandala Nista (lingkaran warna hitam) yaitu tempat peralihan dari luar ke dalam pura [3].

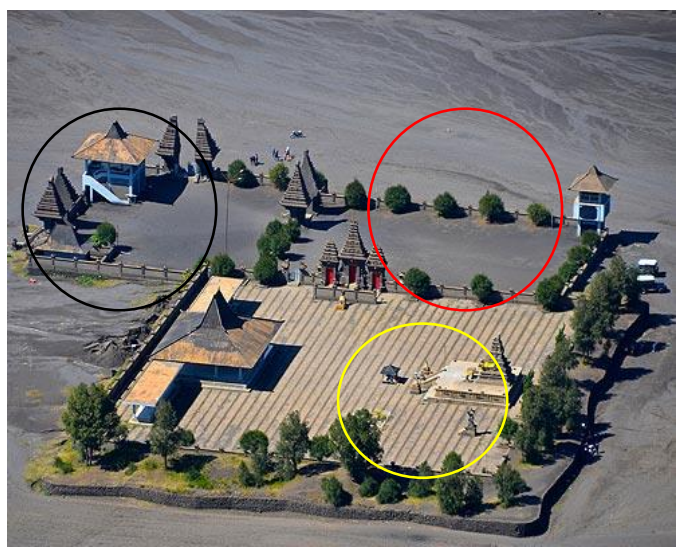

Gambar 1. Pura Poten Luhur

\section{Kebiasaan Masyarakat Tengger}

Keunikan masyarakat suku Tengger adalah cara mereka mereka memakai sarung yang difungsikan untuk mengusir dan mencegah hawa dingin yang menjadi ikim di kawasan lereng Gunung Bromo. Selain itu, untuk penerangan ketika malam hari masih banyak menggunakan lampu petromaks.

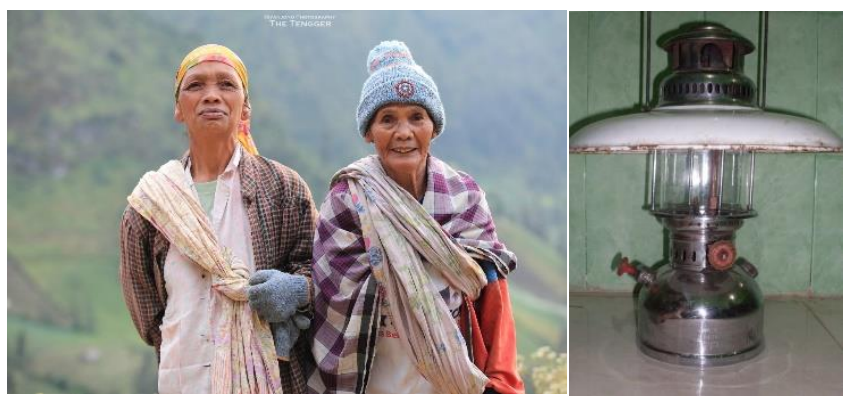

Gambar 2. Sarung (a) dan Lampu Petromaks (b)

\section{METODE DESAIN}

\section{A. Teknik Pengumpulan Data}

Pada perancangan konsep desain interior Hotel Bromo Permai 1 ini dilakukan tahap pengumpulan data melalui beberapa metode. Jenis sumber data pada perancangan konsep 
ini diperoleh dari data primer dan data sekunder. Data-data yang diolah dan dianalisa diperoleh dari sumber data yang meliputi:

\section{- Sumber Data Primer}

Sumber data primer diperoleh dari sumber langsung, peneliti melakukan observasi/survey langsung ke tempat objek yang sedang dikaji, wawancara dengan responden dan penyebaran kuesioner yang berkaitan dengan topik pembahasan perancangan. Data primer meliputi observasi Tempat/lokasi perancangan, Informan/wawancara, dan Kuesioner.

- Sumber Data Sekunder

Pengumpulan data ini dilakukan dengan cara mengumpulkan data yang relevan terhadap topik pembahasan dari berbagai sumber, seperti buku, website, dan studi lain yang sudah pernah dilakukan terhadap perancangan konsep interior dengan konsep budaya Tengger.

- Studi Literatur

Studi literatur ini diperoleh melalui internet/website berupa artikel atau berita yang terkait dengan topik objek dan bahasan perancangan konsep.

- Studi Pembanding

Studi pembanding bertujuan untuk mendapat referensi data yang bermanfaat dalam proses perancangan konsep Hotel Bromo Permai 1. Dalam hal ini, data dan informasi yang dicari berupa analisa penerapan langgam Modern natural pada obyek.

\section{B. Alur Metodologi Desain}

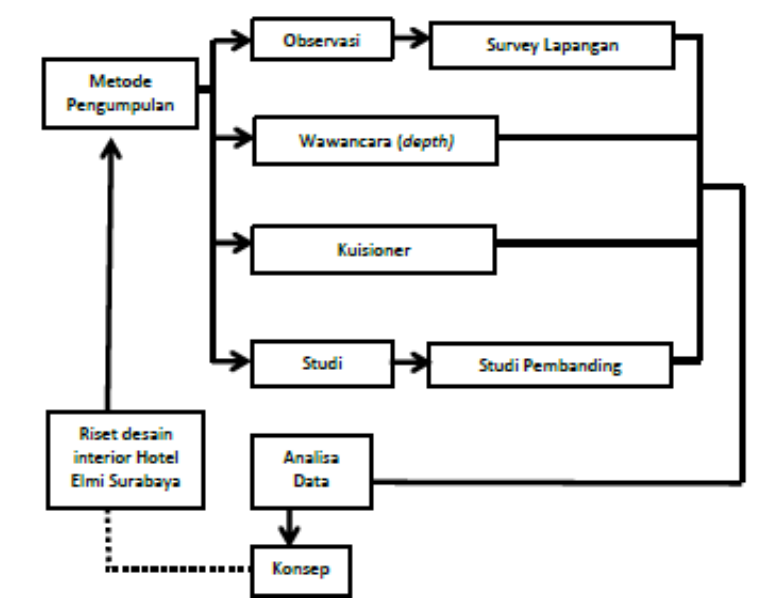

Gambar 3. Alur Metodologi Desain

\section{Analisa Hasil Riset dan Penentuan Konsep}

Metode penentuan konsep interior Hotel Bromo Permai 1 setelah mendapat dan mengumpulkan data-data hasil riset desain dapat dilakukan melalui tahapan-tahapan dalam mendesain, yaitu: Menganalisa ketertarikan pengunjung terhadap konsep dan gagasan-gagasan yang akan diterapkan. Setelah tahap analisa selesai, maka didapatkan hasil akhir yang berupa konsep desain.

\section{KONSEP DESAIN}

Penjabaran dari konsep natural modern dengan sentuhan etnik Tengger dapat direncanakan pada beberapa elemen interior seperti :

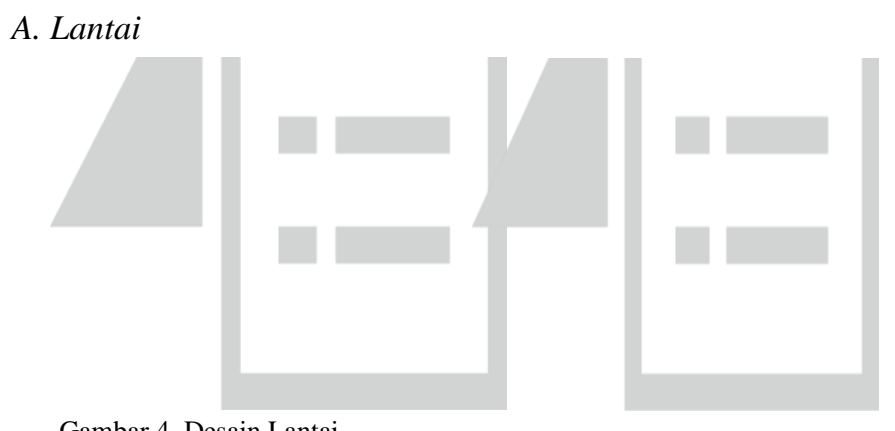

Gambar 4. Desain Lantai

Jenis lantai yang akan diterapkan pada interior Hotel Bromo Permai 1 adalah lantai kayu, granit, dan karpet. Lantai kayu dan granit diterapkan pada area publik, seperti lobi dan restaurant. Perpaduan antara lantai kayu dan granit untuk menggabungkan kesan natural dan modern. Selain itu lantai granit juga membuat ruangan terlihat mewah. Sedangkan pada interior kamar lantai yang digunakan yaitu lantai karpet berwarna krem untuk meredam hawa dingin dari lantai

\section{B. Dinding}

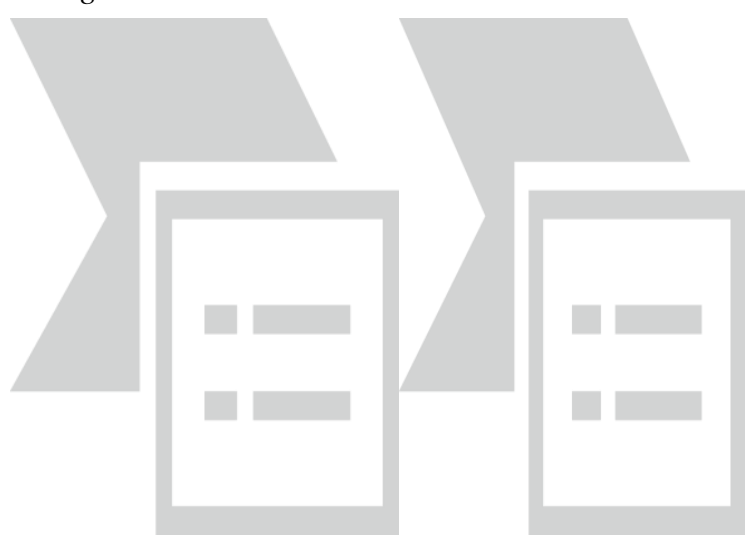

Gambar 5. Desain Dinding

Dinding pada interior Hotel Bromo Permai 1 akan diolah menjadi beberapa jenis. Pada interior ruang publik akan diterapkan dinding dengan material batu dan kayu. Hal ini untuk menunjang konsep natural modern yang akan diterapkan pada interior hotel. Penggunaan material batu pada beberapa titik dinding dapat membuat ruangan terasa kaku sehingga perlu diseimbangkan dengan menerapkan dinding kayu dengan finishing semi-glossy agar tekstur dinding menjadi seimbang. 


\section{Plafond}

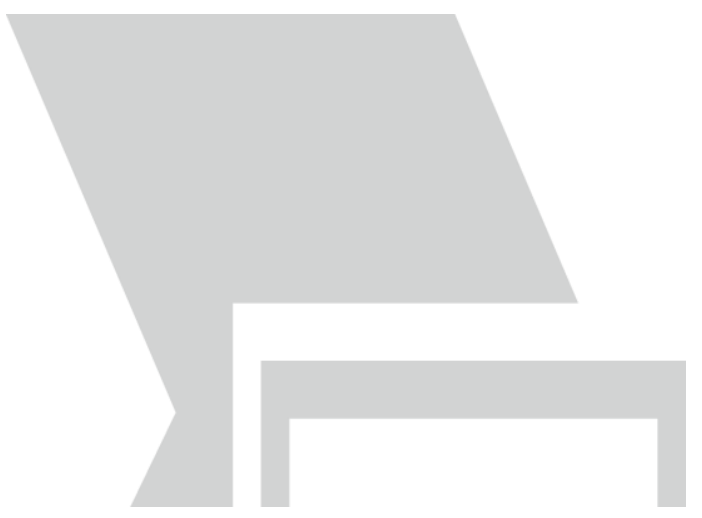

Gambar 6. Artificial Light

Desain pada plafond yang akan diterapkan menggunakan material kayu sehingga membuat ruangan secara keseluruhan terasa hangat.

\section{Furnitur}

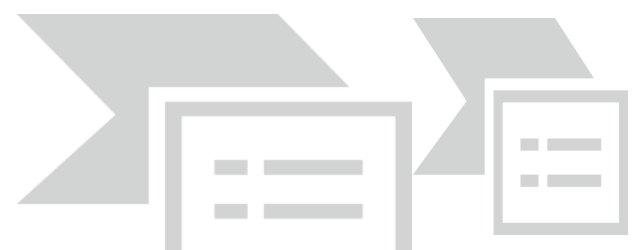

Gambar 7. Furnitur Modern kursi modern (a) dan (b)

Furnitur berbentuk sederhana agar orang bisa merasa lebih tenang ketika berada di dalam ruangan tanpa terganggu oleh bentuk - bentuk yang rumit.

\section{E. Pencahayaan}

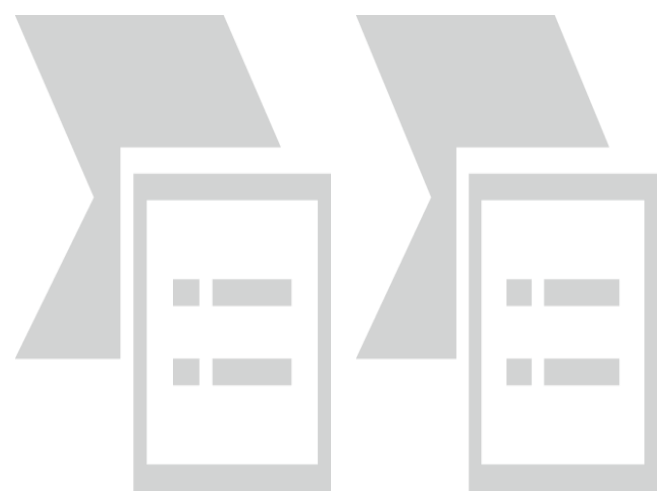

Gambar 8. Lighting model 1 (a) dan model 2 (b)

Pencahayaan yang akan diterapkan adalah lampu artifisial (buatan) untuk menambah kesan dramatis dan mewah pada sebuah ruangan.

\section{F. Elemen Estetis}

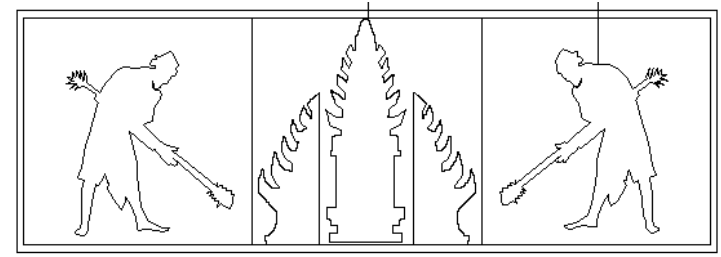

Gambar 9. Elemen Estetis Tari Sodor

Elemen estetis merupakan morfologi bentuk dari beberapa ciri khas etnik Tengger seperti tari sodor diaplikasikan pada elemen estetis dengan material laser cutting.

\section{DESAIN DAN PEMBAHASAN}

\section{A. Lobi Hotel}

Langgam natural ditampilkan melalui pemilihan material kayu yang diterapkan pada beberapa elemen interior seperti dinding dan plafond. Selain sebagai konsep natural, material kayu dapat membuat suasana menjadi hangat.

Di sisi lain langgam etnik tengger diterapkan pada elemen estetis yang terbuat dari metal cutting. Transformasi bentukan elemen estetis berasal dari asal-usul nama Tengger yaitu Roro Anteng dan Joko Seger. Transformasi bentuk tersebut diaplikasikan pada elemen estetis yang menggunakan metal cutting untuk menyatukan konsep etnik tengger dengan modern. Selain dari sisi visual, unsur non-visual seperti indra pendengaran dan penciuman juga di olah dengan menggunakan langgam etnik tengger melalui backsound musik instrumen dan pengharum ruangan atau bunga khas Bromo yang di letakkan di area lobi.
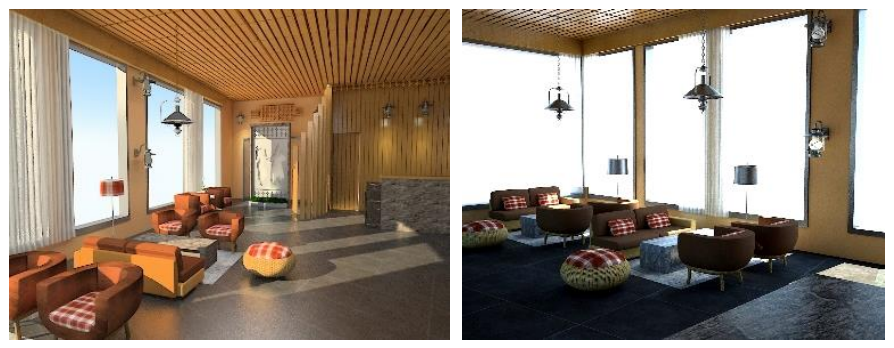

Gambar 10. Hasil Desain Lobi (a) dan (b)

Furnitur yang diterapkan pada lobi terbuat dari kayu dan rotan untuk mendukung konsep natural. Pada bagian puff kursi dibuat serupa yakni memakai motif sarung khas suku Tengger, sehingga dapat mendukung konsep etnik tengger.

\section{B. Restaurant Widodaren}

Nuansa ruang yang diterapkan merupakan gabungan antara natural dan modern. Hal ini ditunjukkan dari penggunaan dinding dan plafond kayu agar suasana yang diciptakan menjadi hangat karena suhu di Gunung Bromo sangat rendah terutama pada malam hari. Pada beberapa bagian menggunakan dinding batu untuk menerapkan kesan kawah Gunung Bromo. Sedangkan konsep modern diterapkan pada bentukan furnitur yang ada di restaurant agar suasana restaurant tidak terlalu monoton. 


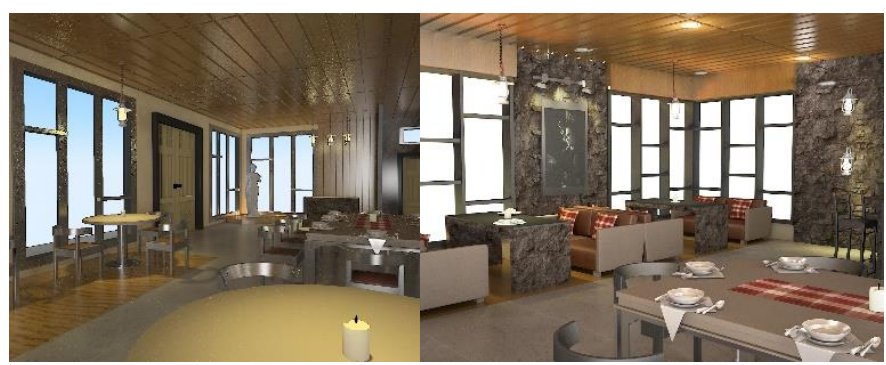

Gambar 11. Hasil Desain Restaurant (a) dan (b)

Elemen estetis yang diterapkan pada restaurant merupakan transformasi bentuk dari ciri khas etnik Tengger. Elemen estetis yang menampilkan Tarian Sodor yang dilakukan masyarakat Tengger ketika melakukan upacara adat. Motif tersebut diaplikasikan pada metal cutting. Pengolahan bentuk furnitur juga diperhatikan agar konsep natural modern etnik Tengger dapat seimbang namun tetap nyaman bagi pengunjung. Kain motif yang diaplikasikan pada puff atau dudukan furnitur merupakan motif kain sarung yang selalu digunakan oleh masyarakat Tengger sehari-hari

\section{Cottage}

Suasana yang berusaha diciptakan pada cottage adalah suasana hangat. Untuk menciptakan nuansa hangat diperlukan material yang dapat menghangatkan ruangan. Material kayu dapat mendukung konsep natural, selain itu dapat menciptakan nuansa hangat pada ruangan. Material kayu diterapkan pada lantai,plafon, dan beberapa dinding.

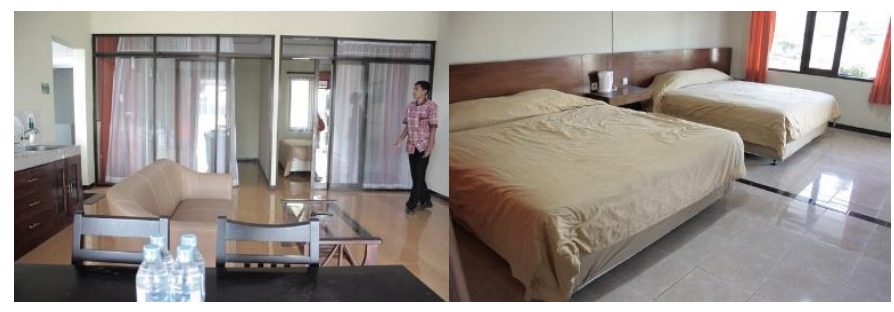

Gambar 12. Foto Eksisting Cottage (a) dan (b)

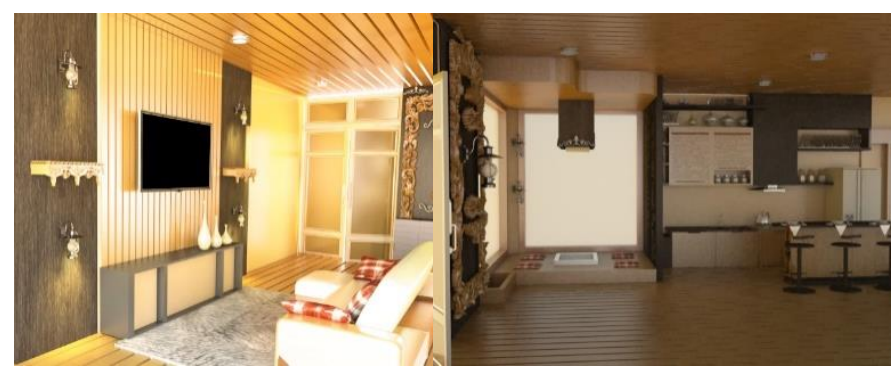

Gambar 13. Hasil Desain Cottage (a) dan (b)

\section{KESIMPULAN DAN SARAN}

\section{A. Kesimpulan}

Dari pembahasan mengenai Redesain Hotel Bromo Permai 1 dengan konsep Naturan Modern dengan Sentuhan Etnik Tengger, dapat disimpulkan beberapa hal, antara lain:
1. Konsep natural modern dengan kombinasi etnik Tengger dapat diaplikasikan pada objek desain untuk menjadi daya tarik bagi para wisatawan baik asing maupun lokal karena konsep ini cukup berbeda dibanding beberapa hotel sekelas di area Taman Nasional Gunung Bromo.

2. Langgam Modern ditampilkan melalui pemilihan warnawarna monochrome, material dengan finishing glossy seperti metal.

3. Sentuhan etnik Tengger lebih ditunjukan dengan adanya tranformasi bentuk kebudayaan seperti asal - usul, tarian, dan pemandangan Gunung Bromo yang diaplikasikan pada elemen estetis ruang.

4. Langgam natural modern dan etnik Tengger dapat disandingkan menjadi suatu satu-kesatuan desain yang baik dengan memadukan unsur-unsur kedua buah langgam pada elemen-elemen interior.

5. Sirkulasi yang efektif dan efisien pada sebuah hotel dapat di desain dengan memperhatikan kedekatan area satu dan lainnya serta akses masuk dan keluar pada sebuah ruang (hubungan dan sirkulasi ruang) yang sangat dipengaruhi oleh alur kegiatan dan oprasional hotel.

\section{B. Saran}

Beberapa saran yang menjadi pertimbangan dalam proses Redesain Hotel Bromo Permai 1 Berkonsep Natural Modern dengan Sentuhan Etnik Tengger:

1. Manajemen anggaran biaya harus diperhatikan dengan memilih material yang ekonomis namun tetap dapat menampilkan ciri khas dari Natural Modern Tengger.

2. Keberadaan hotel berbintang 3 yang semakin banyak di area Bromo harus ditanggapi secara positif oleh pihak-pihak manajemen hotel dengan menerapkan konsep desain yang menarik dan berbeda dari kebanyakan desain hotel sekelasnya.

\section{DAFTAR PUSTAKA}

[1] Ikhwanuddin. Menggali Pemikiran Posmodernisme Dalam Arsitektur. Jogjakarta: Gajah Mada University Press. (2005)

[2] Wawan E Kuswandoro. Budaya Dan Kearifan Lokal Tengger. Jurnal. [pdf]. Available: http://www.lecture.ub.ac.id

[3] Johanes Randy Prakoso. Mengenal Pura Poten, Tempat Ibadah Suku Tengger di Bromo. Artikel. [online]. Available: http://Travel.detik.com 